Rev. Sociedad \& Equidad № 3, Enero de 2012.

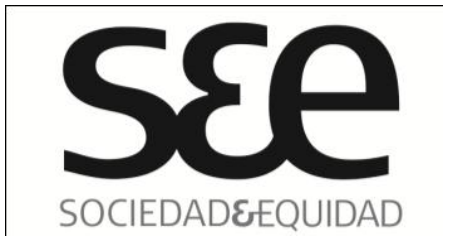

\section{Teatro del Oprimido: dispositivo crítico para la Psicología Social Comunitaria}

\author{
Theater of the Opressed: a critical device for \\ Community Social Psychology
}

\author{
Isabel Puga Rayo ( $\left.{ }^{1}\right)$ \\ Investigadora Independiente \\ Chile \\ isabel.puga@gmail.com
}

\title{
RESUMEN
}

El artículo presenta una revisión teórica que tiene por objeto analizar la compatibilidad de los fundamentos del Teatro del Oprimido con el paradigma de la intervención social en Psicología Social Comunitaria. La investigación consiste en un análisis comparativo entre las propuestas políticas y técnicas de los mismos e identifica algunos procesos psicosociales que la práctica del Teatro del Oprimido promueve en los grupos con los que trabaja. El estudio reveló que el Teatro del Oprimido, como teatro comunitario, ofrece estrategias prácticas para activar procesos psicosociales que han sido investigados por la Psicología Social Comunitaria, tales como el ejercicio del poder, la problematización, la deshabituación, la concientización y la desnaturalización, entre otros. Estos se ejercitan desde el lenguaje corporal y la experimentación de la realidad en escena, cumpliendo con los objetivos principales de la Psicología Social Comunitaria.

\section{ABSTRACT}

This article presents a literature review with the aim of analyzing the compatibility between the principles of the Theater of the Oppressed and the paradigm of social intervention in Community Social Psychology. The research consists of a comparative analysis of the political and technical proposals of both and identifies some psychosocial processes that the TO promotes among the groups that it works with. The study revealed that the TO, as an community theater, offers practical strategies to activate psychosocial processes that have been investigated by CSP, such as the exercise of power, problematization, dishabituation, awareness raising and disnaturalization, among others. These are exercised using body language and experimenting reality in the scene, thus reaching the aim of CSP.

\footnotetext{
${ }^{1}$ La autora es Psicóloga e investigadora independiente. Ha participado en seminarios de formación del Centro del Teatro del Oprimido en Río de Janeiro, Brasil, e investigado sobre la práctica del Teatro del Oprimido en países como Argentina y Uruguay.
} 


\section{S\&e}

PALABRAS CLAVES: Teatro del Oprimido, Psicología Social Comunitaria, metodología de trabajo comunitario, teatro social, procesos psicosociales comunitarios.

KEYWORDS: Theater of the Opressed, Community Social Psychology, community work methodology, social theater, community psychosocial processes.

\section{Introducción}

La Psicología Comunitaria nace formalmente en Estados Unidos, en los años sesenta, de la mano de la Psicología Clínica, pero renace en América Latina a partir del decenio siguiente, apoyándose en la Psicología Social y en otras ciencias sociales. En Estados Unidos, la disciplina se presenta bajo la denominación habitual de Psicología Comunitaria y tiende a estar más directamente asociada a las funciones de asistencia y de protección social, especialmente en lo que concierne a la Salud. En América Latina, surge la denominación de Psicología Social Comunitaria y está más bien relacionada con la meta del cambio social, enraizada en el compromiso por parte de los intelectuales, de promover la liberación de las comunidades oprimidas, generar procesos de autogestión y luchar contra la marginación y la pobreza (Musitu, Herrero, Cantera \& Montenegro, 2004). Se entiende desde esta perspectiva que para "maximizar la salud de los ciudadanos, es indispensable el acceso a la educación, a la cultura, a la vivienda, al ocio y la salubridad, en relaciones más dignas e igualitarias" (Cruz, Freitas \& Amoretti, 2008:93).

La Psicología Social Comunitaria, según la definición de una de sus pioneras y principales exponentes, Maritza Montero, "se orienta hacia la intervención crítica para la transformación social, facilitando y fortaleciendo los procesos psicosociales que posibilitan el desarrollo de comunidades autogestionadas en la solución de sus problemas" (Montero, 2004: 35), estudiando para ello las relaciones de poder y de control sobre las circunstancias de vida, así como su efecto sobre dichos procesos psicosociales.

El objeto de estudio e intervención es para esta disciplina el nivel supraindividual: el grupo, la comunidad, la organización o las transacciones entre el sistema social, las poblaciones y los individuos. Es decir, su objeto característico se sitúa en la relación de lo social (condiciones sociales) y lo individual (procesos psicológicos), asumiendo las condiciones sociales tales como los sistemas ideológicos y estructuras intergrupales (Ayestarán, 1996 en Alfaro, 2000).

En términos generales, se comparte la noción de que la Psicología Comunitaria es aquella que trata de la comunidad y que reconoce en ésta su rol activo en la intervención. Esta definición permite delimitar lo comunitario y lo asistencial con bastante claridad: "si se excluye el rol activo de la comunidad, podría 


\section{SEe}

tratarse de aplicaciones psicológicas concernientes a la salud, la educación, el asesoramiento; aspectos específicamente clínicos que, aunque tengan lugar en el territorio propio de la comunidad, no implicarían un trabajo comunitario, pues no contarían con la participación de quienes integran la comunidad a la cual están dirigidas las acciones interventivas" (Montero, 2004:31).

A su vez, la Psicología Social Comunitaria se distingue por el énfasis puesto en el desarrollo de las fortalezas y capacidades de los grupos, más que en las debilidades y carencias de éstos. Sin embargo, las estrategias metodológicas empleadas actualmente por la Psicología Comunitaria han sido cuestionadas en su adecuación para comprender y abordar los problemas comunitarios (Wiesenfeld, 2009). Podemos decir que en Chile, la práctica de la Psicología Comunitaria ha desvirtuado el rumbo previsto por los pioneros de la disciplina, al vincularse estrechamente a los lineamientos establecidos por las políticas públicas instituidas por los gobiernos chilenos posteriores a la dictadura militar, que si bien focalizan la intervención en los sectores excluidos de la sociedad, tal como se planteaba fundacionalmente la Psicología Social Comunitaria, han situado la acción interventiva en el plano individual y en función de los recursos o competencias de los sujetos para integrarse en sistemas sociales, los cuales no son puestos en la mira de la intervención (Rozas, 2009).

Tal como Alfaro (2004) advierte, en nuestro país priman los modelos interventivos como el de competencias, estrés psicosocial o resiliencia, que responden a la tradición norteamericana funcionalista, mas no hallan iguales oportunidades las estrategias orientadas al cambio social, cercanas a la Educación Popular y otros movimientos latinoamericanos.

En este sentido, es importante analizar las características asistencialistas de muchos proyectos que observamos diariamente. Estos no concuerdan con los principios de la Psicología Social Comunitaria, sino que al contrario, restan potencia al sujeto y retroalimentan la miseria mediante prácticas asistencialistas que algunos autores han acertado en llamar prácticas de exclusión (Cruz, Freitas \& Amoretti, 2008).

De la misma forma, otros investigadores latinoamericanos han alertado sobre esta situación, sosteniendo que las intervenciones están comúnmente dirigidas al afrontamiento o minimización de las problemáticas puntuales vividas por las personas en vez de centrarse en la formación de una conciencia crítica y comprometida, que pueda contribuir a que las personas tengan un sentido de comunidad, colectivo, solidario y dirigido hacia una vida más justa (Freitas, 2002). Se hace necesario que las prácticas comunitarias abarquen las necesidades inmediatas y puntuales de las comunidades con una mirada en el proyecto político sobre el cual se asientan las posibilidades de continuidad, de futuro y de superación de las condiciones generadoras de tales problemas (Freitas, 2000 en Freitas 2002). 


\section{SEe \\ SOCIEDADEEQUIDAD}

Precisaremos, de todas formas, que el concepto de intervención utilizado tanto en la propia Psicología Comunitaria como en el discurso que se impulsa desde las políticas sociales del Estado, es problemático. Esto, pues, remite a una acción que es planificada y ejecutada bajo supuestos que le son ajenos a la comunidad, haciendo de ella un objeto del trabajo psicosocial y no una suma de sujetos dialogantes con el investigador/actor y constructores del trabajo que se decide compartidamente. Si bien es coherente que las políticas sociales asistencialistas sostengan el carácter interventivo de su trabajo, es peligroso que la PSC haga uso del mismo concepto porque se contrapone a los principios orientadores de la disciplina que hablan de transformación, empoderamiento y control de la propia comunidad sobre su devenir histórico. Entendiendo que el lenguaje construye realidades, llamaremos en adelante práctica comunitaria a lo que equívocamente llamamos intervención comunitaria.

Todo lo anterior nos lleva a pensar en la necesidad de nuevos dispositivos para la Psicología Comunitaria, y es justamente desde esta inquietud que el presente artículo pretende dar a conocer algunas de las ventajas que ofrece el Teatro del Oprimido como metodología, tomando en cuenta que la Psicología Social Comunitaria se ha manifestado abierta a la pluralidad de modos de producir conocimiento y transformación, y que ha definido al arte como un elemento del saber popular y un vehículo para la concientización en tanto expresión de libertad y potencia de ideas y deseos (Freitas, 2002). El lenguaje teatral resulta entonces un recurso válido para la disciplina.

Nos centraremos aquí en la problemática política que el Teatro del Oprimido visibiliza y moviliza en su práctica a través de la activación de procesos psicosociales que han sido y debieran ser de interés para la Psicología Social Comunitaria según las definiciones que revisamos anteriormente, procesos que estarían necesariamente implicados en el ejercicio de producir transformaciones sociales mediante cambios en las relaciones de poder, tales como la participación, problematización, deshabituación, desideologización y concientización.

\section{La propuesta del Teatro del Oprimido: principios y trayectoria}

En Brasil, en la década del sesenta, un dramaturgo llamado Augusto Boal renovó el teatro latinoamericano desde una concepción del arte dramático más acorde con las urgencias de su tiempo histórico. Boal contribuyó como actor y director artístico en distintos países de Latinoamérica, Europa y África, y aportó en la construcción de un sistema de ejercicios, juegos y técnicas teatrales, imaginando una modalidad de trabajo socio-comunitaria que tuviera el lenguaje teatral como herramienta catalizadora. De estas experiencias surge el Teatro del Oprimido (Boal, 1974). 


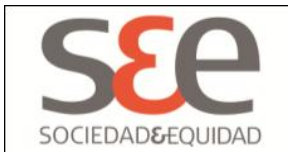

El Teatro del Oprimido consiste, a grandes rasgos, en entregarle a las personas los modos de producción teatral para que se reapropien de un lenguaje artístico que es propio de todo ser humano y no restrictivo para ciertas clases. Este método persigue la desmecanización física e intelectual de los participantes y la democratización del teatro, estableciendo condiciones prácticas para que las personas hagan uso del lenguaje teatral y amplíen sus posibilidades de expresión, a través de una comunicación directa, activa y propositiva (Grupo de Teatro del Oprimido Rosario, 2008). Boal afirma que la primera palabra del vocabulario teatral es el cuerpo humano, principal fuente de sonido y movimiento. Por eso, para dominar los medios de producción del teatro, el hombre tiene que, en primer lugar, dominar su propio cuerpo, conocer su propio cuerpo, para después tornarlo más expresivo.

Dicho lenguaje teatral se utiliza para facilitar la identificación de las situaciones de opresión que las personas viven cotidianamente, los mecanismos de poder en los que están inmersos, para luego ensayar alternativas en las que son las propias personas oprimidas las protagonistas de un accionar que busca transformar las relaciones de opresión en las que viven. Éstas son abordadas escénicamente en un marco de creación colectiva (Boal, 1974; 1980, 1982, 1998). El efecto que propone el Teatro del Oprimido es magnificar y estimular el deseo de transformar la realidad, y para ello se apoya en dos principios fundamentales:1) ayudar al espectador a transformarse en un protagonista de la acción dramática, para que pueda; 2) transponer a la vida real acciones que ha ensayado en la práctica teatral.

El Teatro del Oprimido es un teatro de investigación y de acción, un "teatroensayo" donde el grupo oprimido prepara las acciones que podrán permitirle enfrentarse a las situaciones de opresión. Para conseguirlo, debe destruirse la barrera entre actores y no actores; las personas participantes tendrán que figurar a veces como actores y otras veces como espectadores de forma dinámica, por esto es que Boal hablaba de Espect-actores para referirse a los participantes; todos deben protagonizar las necesarias transformaciones de la sociedad, así como también suprimir la propiedad privada del personaje, en tanto cada actor puede representar a cada personaje. Estas formas pretenden suministrarle al Espect-actor una insatisfacción y desde ahí el deseo de aplicar en la realidad el acto ensayado en el teatro (Boal, 1980).

Boal estaba en contra de dar a los personajes el poder de pensar y de actuar en lugar del espectador: "no basta consumir cultura, es necesario producirla. No basta gozar del arte, es necesario ser artista; no basta producir ideas, es necesario transformarlas en actos sociales concretos y continuados" (Boal, 2009: 18). 


\section{SEe}

Todas las formas de teatro deben servir al espectador para salir de su condición de espectador. Él debe ensayar acciones como protagonista de la acción dramática, inclusive si se equivoca. Si se equivoca, se equivoca en la acción y descubre desde su punto de vista que esta acción es mala (Boal, 1980: 228).

Una de las principales formas del Teatro del Oprimido se denomina Teatro Foro; en ella los espectadores se saben constructores de una acción dramática y pueden aprovechar ese proceso constructor para evaluar las dificultades y alternativas que ofrece preparar una acción futura (Boal 1980; 2004; 2009). En resumen, el teatro foro es una especie de lucha, o de juego que tiene sus reglas. El objetivo fundamental es la integración del escenario con la platea, bajo el monitoreo de quien ejerce como nexo de la interrelación entre ambos espacios. En la escena el protagonista debe ser el oprimido y los personajes deben estar claramente caracterizados para que la opresión sea expuesta con veracidad y así pueda el espectador identificarse con la acción y facilitar la aproximación objetiva y solidaria con el oprimido. Si en una determinada situación escenificada el espectador no se identifica con el desarrollo de los hechos, el monitor invita a los espectadores a entrar en escena sustituyendo a los actores y presentando alternativas para el deshecho de la pieza. El monitor auxilia la construcción del texto y el debate con las personas presentes, haciendo que la intervención del público sea quien defina el final de la escena (Boal, 1980).

Dentro de una práctica de Teatro Foro, los monitores del Teatro del Oprimido deben ayudar a cada participante a descubrir lo que ya sabe: traer a su conciencia su propio conocimiento. No se trata de decir "haga esto o aquello, porque así se hace", sino “y si hiciésemos esto o aquello, ¿cómo sería?". Aun cuando los participantes hagan alguna cosa admirable, se deben pedir alternativas: "y si fuese diferente, cómo sería". El "curinga" o monitor debe saber funcionar como apoyo inductor, siempre haciendo preguntas, levantando dudas donde haya certezas, ofreciendo certezas donde haya dudas, que siempre existen. Eso sí, en el final de cada sesión sí se debe decidir qué hacer, cómo hacerlo y cuándo. ¡Hay que hacer! (Boal, 2009).

Este teatro implica un proceso de investigación permanente que ha generado también su propia teoría, la cual se encuentra hoy en distintas publicaciones de Boal (2009). Desde la década del 60, en que el dramaturgo desarrolló el Teatro del Oprimido, hasta nuestra fecha, este teatro revolucionario ha sido experimentado en diversos contextos socio-históricos, insertándose tanto en las dinámicas de poder propias de la opresión dictatorial latinoamericana, en las que se objetivaba fácilmente al opresor, como en contextos demócratas en que el poder no es ejercido necesariamente desde un afuera, sino desde la internalización subjetiva del poder por los individuos (Boal, 2004). De esta técnica que recorrió el mundo promoviendo 


\section{SEe \\ SOCIEDADEEQUIDAD}

experiencias revolucionarias a nivel local, que trabajó con las experiencias de opresión de pequeños grupos de personas, haciendo que se identificaran las formas en que el poder se ejerce en la realidad y permitiendo una nueva constitución de los sujetos mediante la modificación de sus relaciones de poder, existen frágiles registros en Chile, como relataron Shultz y López a la autora (Puga, 2010).

A lo largo de casi cuatro décadas, el Teatro del Oprimido ha ayudado a traspasar bloqueos, crear puentes de diálogo y estimular acciones concretas para la superación de realidades opresivas. El impacto de esas experiencias, las dificultades enfrentadas, las alternativas encontradas y los desafíos identificados para el futuro, fueron analizados en la primera Conferencia de Teatro del Oprimido, realizada del 20 al 26 de Julio de 2009, en Río de Janeiro, por el Centro de Teatro del Oprimido (Boal, 2009).

El Teatro del Oprimido lo practican hoy en más de 70 países, campesinos, trabajadores, maestros, estudiantes, artistas, trabajadores sociales y psicoterapeutas. Esto es así pues ya existen grupos especializados en Teatro del Oprimido en muchos lugares, quienes han aprendido las técnicas y las socializan en sus contextos locales, lo cual lamentablemente aún no ha ocurrido en Chile.

Ahora bien: ¿Qué ofrece el Teatro del Oprimido como metodología para la Psicología Social Comunitaria?

\section{Convergencias del Teatro del Oprimido y la Psicología Social Comunitaria: una mirada política compartida}

La Psicología Social Comunitaria destaca la dimensión política de su quehacer, que atañe al carácter y finalidad del conocimiento producido, así como a su ámbito de aplicación y efectos sociales. Montero (2004), señala que:

La política se refiere a la esfera de lo público, al ámbito de la ciudadanía y a cómo nos relacionamos con otras personas en ella. Asimismo, se refiere al poder y a sus líneas de acción, lo cual constituye su núcleo central. Eso supone hacer y decir dentro de la sociedad en que vivimos; por lo tanto, tiene que ver con el tener voz y hacerla oír y con el generar espacios para que aquellos que han sido relegados al silencio puedan hablar y ser escuchados y se establezca el diálogo. Por eso, la relación dialógica que se propone en la Psicología Social Comunitaria, al generar un espacio de acción transformadora, crea al mismo tiempo un espacio de acción ciudadana que permite la expresión de las comunidades y, por lo tanto, es ejercicio de la democracia (Montero, 2004: 49). 


\section{SSe}

En el Teatro del Oprimido se inventa y produce conocimiento y acción con clara conciencia política, delimitando para quién es el conocimiento producido y sus efectos. Al igual que la Psicología Social Comunitaria, el Teatro del Oprimido adopta una concepción de la sociedad como conflicto, y en ella, los problemas sociales actuales son vistos como producto de las relaciones sociales asimétricas. Se asume la existencia de una realidad opresora producto de ciertas condiciones históricas y prácticas sociales, y su quehacer se enfoca hacia el trabajo con grupos, comunidades u organizaciones particulares, que son socialmente, culturalmente, políticamente, 0 por razones de raza o sexualidad, desposeídos de su derecho al diálogo.

Santos (2010) manifiesta, "partimos del principio de que el Teatro del Oprimido es del oprimido y debe ser hecho por el oprimido y para el oprimido". Existe entonces un posicionamiento y compromiso por parte de los trabajadores del TO para con el grupo o comunidad con el cual interactúan. Para ellos, los oprimidos son sujetos, y el teatro es su lenguaje. Pero no solo se requiere del compromiso de los monitores en el Teatro del Oprimido, ya que al igual que en la PSC y otras perspectivas participativas, es fundamental el compromiso de los miembros de la comunidad para el trabajo que se lleva a cabo. El desafío de una práctica con Teatro del Oprimido está justamente en generar ese compromiso dentro del grupo con que se trabaja; por eso es importante que el grupo se conozca, que tengan una identidad grupal que pueda potenciarse y un lugar donde ejercer como tal con los aprendizajes obtenidos.

La Psicología Social Comunitaria se define como una psicología de relaciones creada para un mundo relacional, donde interesan las formas específicas de relación entre personas unidas por lazos identitarios construidos en relaciones históricamente establecidas, que a su vez construyen y delimitan un campo: la comunidad. No es posible, entonces, llevar a cabo acciones comunitarias a partir de una concepción fragmentaria de la comunidad, construida a partir de la sumatoria de individuos aislados (Montero, 2004). En el Teatro del Oprimido, coincidentemente, se trabaja con grupos o colectivos de personas, puesto que no es posible concebir el fenómeno de la opresión sin enmarcarlo en una relación social que, además, es histórica, en tanto responde a un momento y un espacio determinado. Se es oprimido cuando hay opresor, aunque a veces éste no sea una figura objetiva o concreta, y los sujetos vivan oprimidos a causa de la internalización de mecanismos represores del sistema social en que se encuentran. Del mismo modo, la liberación o desopresión solo es posible cuando hay otros de los que liberarse y con los cuales liberarse.

\section{Algunos procesos psicosociales activados en el ejercicio con Teatro del Oprimido}

La participación es entonces un componente fundamental, ya que al igual como se comprende en la Psicología Social Comunitaria, ésta es un fenómeno indicador de transformación psicosocial (Montero, 1996), principal objetivo de ambas propuestas. 


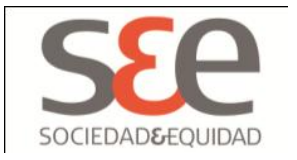

Por eso, para ser practicado adecuadamente, el Teatro del Oprimido precisa que los participantes posean plena libertad de elección: para participar, elegir los temas de su interés y definir metas y estrategias de acción, dentro de los límites de sus posibilidades. El grupo precisa apropiarse de los medios de producción teatral para expresar deseos y necesidades de transformación de la realidad que lo oprime, estando conciente de los desafíos y riesgos para tornarlos públicos y determinarse a enfrentarlos (Santos, 2010).

Ahora bien, tomando como elemento principal la participación en este tipo de prácticas comunitarias, pasemos a analizar cuáles son los otros procesos psicosociales que activa el trabajo con el Teatro del Oprimido y que son necesarios para cumplir con su objetivo.

Según Boal (2009), las sociedades son espectaculares en el sentido estético de la palabra, esto es, como organización sensorial de un acto, una relación humana, un evento. Todas las sociedades humanas son espectaculares en su cotidiano y producen espectáculos en momentos especiales. Son espectaculares como forma de organización social, también cuando no son concientes de ello. Todas las relaciones sociales en la vida cotidiana son estructuradas como espectáculos en los cuales se exhiben las relaciones de poder existentes entre los integrantes de algún segmento social: el uso del espacio, el lenguaje del cuerpo, la elección de las palabras y la modulación de las voces, gestos y movimientos corporales; todo lo que puede ser revelado por los sentidos denuncia relaciones de poder. Cada participante de esos espectáculos conoce su lugar, sabe su papel, con él se conforma o intenta modificarlo según las armas de que dispone. Ninguna sociedad sobreviviría sin ser espectacular y sin espectáculos, ya que ambos tienen una función civilizadora.

Es sustancial esta metáfora de la sociedad como espectáculo. Es debido a la condición espectacular de la sociedad que el teatro se presenta también como una vía para trabajar ciertos procesos psicosociales que le interesan a la Psicología Social Comunitaria. Si bien es el cambio social el objetivo final del Teatro del Oprimido, existen varios procesos psicosociales que el Teatro del Oprimido ejercita, pues ha identificado como medios para cumplir su objetivo. Muchos de estos han sido investigados por la Psicología Social Comunitaria, tales como el ejercicio del poder, la problematización, la habituación, la concientización y la naturalización, entre otros.

Para la Psicología Social Comunitaria, el poder es algo inherente a todas las relaciones humanas y tiene aspectos tanto positivos como negativos que deben ser considerados cuando se trata de procesos comunitarios. Montero (2003) sostiene que:

Las expresiones asimétricas del uso del poder, aquellas en las cuales un polo de la relación de poder concentra la mayoría o la totalidad de los recursos deseados, generan situaciones cuyo desequilibrio puede producir efectos 


\section{SEe}

patológicos sobre las personas, las relaciones familiares e institucionales, afectando en general todas las expresiones de la inter-subjetividad. Tanto el abuso como la ausencia de poder, su exceso y su defecto, son causa de procesos psicológicos con consecuencias en el campo psicosocial (Montero, 2003:1).

El poder es un problema, también, cuando se ignora que se lo posee. Muchas veces el quehacer comunitario se enmarca en comunidades que poseen bajos recursos económicos, en comunidades excluidas de todos o de gran parte de los beneficios sociales. Se suele pensar que esos grupos también carecen de todo poder.

Esta consideración es un modo de naturalizar una situación en la cual los desposeídos, los pobres, los excluidos, y en general todos los grupos sociales que no disfrutan del poder estatuido ni de condiciones socioeconómicas dignas, son vistos como débiles, incapaces, privados de toda posibilidad de transformar su forma de vida (Montero, 2003: 2).

Para el Teatro del Oprimido, el opresor produce en el oprimido dos tipos de reacción: la sumisión y la subversión. Se entiende que todo oprimido es un subversivo sometido, pues muchas veces la opresión se internaliza y la propia víctima la acepta. La investigación que promueve la práctica del Teatro del Oprimido se centra en identificar en qué momento el oprimido aún podría haber optado por otras soluciones, en vez de permitir que la historia avanzase hacia el final opresivo (Boal, 1998). El Teatro del Oprimido persigue entonces dinamizar el carácter subversivo que existe en cada oprimido a través de la participación activa en la vida social y política. También lo hace a través de la problematización de la existencia, permitiéndole cuestionar dogmas y certezas, hábitos y costumbres, para, tal como diría Freire (2005), negar al mundo como una realidad ausente de los hombres.

El postulado fundamental del conjunto del Teatro del Oprimido es éste: si el oprimido mismo (y no el artista en su nombre) lleva a cabo una acción, dicha acción, realizada en la ficción teatral, le dará la capacidad de autoactivarse para realizarla en la vida real. Como el objetivo del Teatro del Oprimido no es terminar un ciclo, provocar una catarsis, cerrar un proceso, sino, por el contrario, comenzar un proceso, promover la iniciativa individual, estimular la creatividad transformadora de los espect-actores al convertirlos en protagonistas, las transformaciones iniciadas no deberían terminarse en el ámbito del fenómeno estético, sino trasladarse a la vida real (Boal, 2009). 


\section{S\&e}

Mucho más importante que llegar a una buena solución, es provocar un buen debate, pues lo que conduce a la autoactivación de los espect-actores es el debate, no la solución que por casualidad pueda encontrarse. El debate, el conflicto de ideas, la dialéctica, la argumentación y la réplica, todo ello estimula, calienta, enriquece, prepara al espectador para actuar en la vida real. Por tanto, cuando el modelo no es urgente, es decir, cuando no se trata de salir del espectáculo y actuar directamente sobre la realidad, tampoco es necesario encontrar una solución: lo necesario es buscarla (Boal, 2009). En este sentido, el Teatro del Oprimido no es una serie de recetas, de procedimientos liberatorios, un catálogo de soluciones ya conocidas: es, sobre todo, un trabajo concreto sobre una situación concreta, en un momento dado, en un lugar determinado. Es un estudio, un análisis, una investigación. Esto coincide con la idea de dialogicidad que es la base de la pedagogía freiriana y del ejercicio (auto) crítico de la problematización.

La función del curinga o monitor del Teatro del Oprimido va desde la identificación y la representación estética del conflicto, hasta la discusión y viabilidad de las estrategias que posibiliten la transformación de la realidad enseñada. Quien ocupa la función de curinga, debe auxiliar a las personas a descubrir sus potencialidades, a conocerse mejor, a expresar sus ideas y emociones, a analizar sus problemas y a buscar alternativas propias. Podemos decir entonces que al igual que en la Psicología Social Comunitaria, el sujeto externo a la comunidad ocupa el rol de catalizador social, redirigiendo y reorganizando las inquietudes presentes en la comunidad, abriendo espacios de reflexión y de acción. La transformación social la llevan a cabo los miembros de la comunidad.

Ahora bien, el Teatro del Oprimido reconoce que su campo de acción está en las micro relaciones de poder y que si bien la idea es transformar en teatro todos los locales, grandes o pequeños, en el campo o en la ciudad, donde viven y trabajan hombres y mujeres, este es un trabajo que se caracteriza por ser aterrizado y profundo en sus intervenciones y cada intervención es un aporte a la desopresión de la humanidad. Boal diría que "un grano de arena es un grano; millones, son una playa" (Boal, 2009: 213).

En esta línea, Boal instaura el término de "multiplicación" para referirse al acto de expandir la práctica del Teatro del Oprimido, pues no solo se dedican sus practicantes a apoyar con sus técnicas a grupos comprometidos con la emancipación comunitaria, sino que también se han creado proyectos de formación de "multiplicadores" dentro de organizaciones de la sociedad civil. La idea es que cada grupo de Teatro del Oprimido formado debe colaborar en alguna acción colectiva de la comunidad donde se presenta. Posterior al evento artístico no se abandona el local como una compañía itinerante que deja el recuerdo y luego viaja a otras ciudades a trabajar: hay que mantener el contacto, formando redes de apoyo, sin tomar por esto el lugar de los oprimidos. 


\section{SEe \\ scanesea}

Siguiendo con el análisis de los procesos psicosociales que pueden activarse a través del ejercicio del Teatro del Oprimido, podemos pensar en que uno de los problemas de las comunidades oprimidas es la enajenación, entendida por Freire (2005) y adoptada por Montero (2004) como una ideología inmovilizante, que pone fuera del sujeto las condiciones de su existencia, haciéndolo vivenciar las condiciones históricas como determinaciones naturales o inmanentes, lo que tiene como consecuencia la vivencia de la imposibilidad de cambiarlas. Desde esta perspectiva freiriana, que inspira también al Teatro del Oprimido, es necesario tener siempre en cuenta entonces la misión educativa de la actividad artística, su carácter pedagógico, y por ende su carácter combativo. El teatro visto de esta forma no es solo un arte, sino un arma desideologizante (Boal, 1998).

Las técnicas del Teatro del Oprimido permiten representar una escena en la que está contenida la visión del mundo imperante, donde los actores identifican y actúan la opresión que viven en su cotidianeidad. Este es un primer ejercicio de concientización, donde se exploran procesos tales como los que Bourdieu entendiera como habituación, al experimentar la alienación muscular impuesta por el trabajo sobre el cuerpo, las máscaras con las que actuamos y los rituales que reproducimos a diario, conceptos de los que Boal hace uso con el fin de tomar conciencia del grado en que la ideología se encarna en el cuerpo social (Boal, 1980). Así, el pensamiento sensible que produce arte es esencial para la liberación de los oprimidos, ya que amplía y profundiza su capacidad de conocer, ejercitando una conciencia corporal tremendamente necesaria para experimentar nuevas posibilidades de acción.

Es sustancial el aporte que en esta línea constituye la utilización del Teatro del Oprimido para la activación de procesos psicosociales como la desideologización, concientización y deshabituación que busca la Psicología Social Comunitaria. En tanto la experimentación de la realidad como escena que permite el teatro con la actuación, es un recurso palpable y concreto para comprender que funcionamos bajo pautas, como diría Bourdieu, o guiones, usando un término del teatro, que nos condicionan.

Lo importante es entonces el ejercicio de tomar conciencia de que estas pautas son condicionantes, pero no determinantes, y en esto el trabajo que promueve el Teatro del Oprimido es paradigmático: el grupo que observa la escena opresora como algo construido por actores, es invitado a participar de aquella escena, ejerciendo el poder de deconstruirla y reconstruirla, experimentándola como una realidad transformable (Boal, 2009).

La meta del Teatro del Oprimido no es llegar a un equilibrio tranquilizador, sino al desequilibrio que conduce a la acción. Su objetivo es dinamizar, y esto se consigue a través de la acción concreta, en escena (Boal, 2002). A esta misma meta se refiere Montero (2004) cuando habla de "movilizar las conciencias". El trabajo de la Psicología Social Comunitaria busca suscitar una movilización transformadora del 


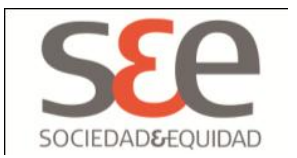

contenido de la conciencia y no generar una conciencia donde no la había. Tal proceso ocurre en las personas, según la autora, debido a su reflexión y acción; no es obra de la imposición de acciones o de ideas de un agente externo al cual se atribuyen poderes especiales. De la misma forma, Boal plantea que la movilización de las conciencias es un primer paso, pero la práctica con TO no debe acabarse en ella. Se necesita un teatro que nos ayude a cambiar la realidad, y "el espectador que va a cambiar su realidad la cambiará con su cuerpo. Se actúa con la conciencia, se actúa con el cuerpo" (Boal, 1980: 227).

No se trata de adaptar ni de crear conciencias, como podría necesitar una psicología normalizadora o un teatro didáctico; se trata de movilizar las conciencias en el ejercicio de la práctica comunitaria, donde interactúan personas externas e internas de la comunidad, con técnicas en constante movimiento y construcción, hacia una realidad que dignifique la existencia de cada participante. Esto se consigue a través de la acción concreta, en escena. Boal dirá: “¡El acto de trasformar es transformador! Transformando la escena, me transformo” (Boal, 2009: 180).

Se va comprendiendo así que el Teatro del Oprimido no es un teatro de espectáculo como convencionalmente estamos acostumbrados a experimentarlo, sino que se trata de un "teatro-ensayo" donde el grupo oprimido prepara las acciones que podrán permitirle enfrentarse a las situaciones de opresión. En este sentido -y Boal es tajante en decirlo- el teatro no reemplazará la acción real, pero puede ayudar para que ésta sea más eficaz. Es una fase preliminar e inferior a la acción real pero muy superior a la discusión abstracta de los problemas referentes a la opresión (Boal, 1980).

Estas formas de teatro popular, en lugar de quitarle algo al espectador, le suministran una insatisfacción, el deseo de aplicar en la realidad el acto ensayado en el teatro (Boal, 1980), lo cual atenta contra la visión naturalizada de la que hablaba Montero (2003), en la que los pobres, los excluidos, y en general todos los grupos sociales que no disfrutan del poder estatuido ni de condiciones socioeconómicas dignas, son vistos como débiles, incapaces, privados de toda posibilidad de transformar su forma de vida.

\section{Conclusiones}

Como pudimos apreciar, en el campo político, las compatibilidades del Teatro del Oprimido con la Psicología Social Comunitaria son sustanciales. Ambos entienden la sociedad como conflicto y se orientan hacia la práctica crítica para la transformación social, facilitando y fortaleciendo los procesos psicosociales que posibilitan el desarrollo de comunidades autogestionadas en la solución de sus problemas, estudiando para ello las relaciones de poder y de control sobre las circunstancias de vida, así como su efecto sobre dichos procesos psicosociales (Montero, 2004; Boal, 1980). Esto es así, pues los trabajadores comunitarios 


\section{s\&e \\ SOCIEDADEEQUIDAD}

declaran una posición frente a la realidad social, y consecuentemente se comprometen con los sujetos con los cuales llevan a cabo la práctica comunitaria, afirmando que el conocimiento producido es del oprimido y debe ser hecho por el oprimido y para el oprimido, cumpliendo ellos un rol catalizador del cambio social.

Encontramos concordancia en el análisis de los procesos psicosociales que activan las prácticas propuestas por el Teatro del Oprimido y la Psicología Social Comunitaria, en tanto se asume que para producir transformaciones sociales se necesitan cambios en las relaciones de poder, y ello implicaría participación, problematización, deshabituación, desideologización y concientización.

Todo lo anterior permite conceptualizar el Teatro del Oprimido como una metodología útil para la praxis de la Psicología Social Comunitaria y sostener que este favorecería el escenario de la acción comunitaria, ya que al ser ideológicamente compatible pudiera entregarle herramientas del lenguaje teatral para llevar a cabo procesos colectivos de empoderamiento y cambio social. Como la Psicología Social Comunitaria se ha manifestado abierta a la pluralidad de modos de producir conocimiento y transformación, aceptando que el conocimiento puede darse en diferentes ámbitos, por diferentes medios, el lenguaje teatral resulta un recurso válido.

Pero no es solo válido. Las compatibilidades son vastas entre ambas perspectivas y permiten seriamente albergar la idea de incorporar el Teatro del Oprimido a la batería metodológica de la Psicología Social Comunitaria, pero resulta aún más convincente la propuesta si rescatamos las bondades que brinda la utilización de un lenguaje teatral para la práctica psicocomunitaria.

El Teatro del Oprimido es un método que respeta los procesos del grupo y de cada persona con su cuerpo, pues dependiendo del tiempo, las técnicas y juegos que se escojan para trabajar con los grupos, el cuerpo va procesando transformaciones en cada etapa de trabajo. Se vive el tránsito desde el bloqueo a la liberación, de forma cautelosa, conciente, vívida y sensorial, que es quizás un recurso mucho más duradero y potente para quien luego de la acción se va a su casa, porque es su cuerpo el que se fue transformado.

Más aún, como técnica, el lenguaje teatral no es ajeno a la gente, lo que permite que cada grupo cultive sus formas, sus temas, sus propias formas de entender los problemas y vías de solucionarlos. El Teatro del Oprimido es un método que permite empoderar a las personas que no reconocen en sí capacidades discursivas y críticas, permitiéndoles liberar desde el cuerpo lo que quieran decir, generando en ellos una gama más amplia de accionar y construir el mundo. El ensayo permite el riesgo, desinhibe y entrega respuestas inmediatas en torno a las consecuencias de la práctica, con un espíritu lúdico y alegre que fomenta la producción artística y genera sentido. 


\section{s\&e \\ SOCIEDADEEQUIDAD}

Por último, el Teatro del Oprimido es un método que prepara a la gente para seguir multiplicándolo, lo cual es fundamental para un trabajo comunitario que quiere independizar a las comunidades de los profesionales expertos.

\section{Referencias Bibliográficas}

Alfaro, J. (2000). Discusiones en Psicología Comunitaria. Textos de Docencia Universitaria. Santiago. Chile: Universidad Diego Portales.

Alfaro, J. (2004). Psicología comunitaria y Políticas sociales: análisis de su desarrollo en Chile. Revista de Psicología Universidad Bolivariana. Babel. Año 1 No 1-2.

Boal, A. (1974). Teatro del Oprimido y otras poéticas políticas. Buenos Aires: Ediciones La Flor.

Boal, A. (2009). A estética do oprimido. Rio de Janeiro: Garamond.

Boal, A. (2004). El arcoiris del deseo. Barcelona: Alba.

Boal, A. (1998). Juegos para actores y no actores. Barcelona: Artes Escénicas.

Boal, A. (1982). Técnicas latinoamericanas de teatro popular. México: Nueva Imagen.

Boal, A. (1980). Teatro del Oprimido: teoría y práctica. México: Nueva Imagen.

Cruz, L., Freitas, M. y Amoretti, J. (2008). Psicología social comunitaria. En Saforcada, J, y Castellá, J. Enfoques conceptuales y técnicos en psicología comunitaria. Buenos Aires: Paidós. (pp. 91-111).

Freire, P. (2005). Pedagogía del Oprimido. Buenos Aires: Siglo XXI Editores.

Freitas, M. (2002). Intersecciones entre sentido de comunidad y vida cotidiana: posibilidades para las prácticas de la Psicología Social Comunitaria. En Pipper, I. (comp.) Política, Sujetos y Resistencia. Debates y Criticas en Psicología Social. Santiago, ARCIS. (pp. 293-306.) 


\section{S\&e}

Grupo de Teatro del Oprimido Rosario (2008). ¿Abandonar la butaca? Una ética de los intercambios. Cuadernos de Campo. Año 2, $N^{0}$ 6. Recuperado de <http://www.pt.calameo.com/books/000049129384149a48319>

Montero M. (2004). Introducción a la Psicología Comunitaria. Buenos Aires: Paidós.

Montero, M. (2003). Teoría y práctica de la Psicología Comunitaria: la tensión entre comunidad y sociedad. Buenos Aires: Paidós.

Montero M. (1999). De la realidad, la verdad y otras ilusiones concretas: Para una epistemología de la Psicología Social Comunitaria. Revista Psykhe Vol 8, $n^{\circ} 1$. (pp. 917).

Montero, M. (1994). Vidas Paralelas. Psicología Comunitaria en Latinoamérica y en Estados Unidos. En Montero, M (coord.). Psicología Social Comunitaria de Montero, México: Colección Fin de Milenio. Universidad de Guadalajara.

Musitu Ochoa G., Herrero Olaizola J., Cantera Espinosa L. \& Montenegro Martínez M. (2004). Introducción a la Psicología Comunitaria. Barcelona: UCO.

Puga, I. (2010). Teatro del Oprimido: una herramienta para la Psicología Social Comunitaria. Tesis para optar al título de psicóloga. Santiago, Universidad ARCIS.

Rozas G. (2009). Desafíos de la Psicología Comunitaria en Chile. Ponencia presentada en $1^{\text {a }}$ Jornada Internacional y $4^{\text {a }}$ Jornada Nacional de Psicología Comunitaria. Santiago de Chile.

Saforcada, E. \& Castellá, J. (2008). Enfoques conceptuales y técnicos en Psicología Comunitaria. Buenos Aires: Paidós.

Santos, B. (2010). A Arte de Curingar. Revista Metaxis, $N^{0} 6$.

Santos, B. (2010). Teatro do Oprimido para empresas privadas. Incompatibilidades, impossibilidades e absurdos. Revista Metaxis, $N^{\circ} 6$.

Wiesenfeld E. (2009). La Psicología Social Comunitaria en América Latina: Mitos, Dilemas y Desafíos. Ponencia presentada en $1^{\text {a }}$ Jornada Internacional y $4^{\mathrm{a}}$ Jornada Nacional de Psicología Comunitaria. Santiago de Chile. 